\title{
Urgences
}

\section{Paul Chanel Malenfant, En tout état de corps, Trois-Rivières, Écrits des Forges, 1985, 80 p.}

\section{Danielle Fournier}

Numéro 26, décembre 1989

Des textes qui chantent

URI : https://id.erudit.org/iderudit/025561ar

DOI : https://doi.org/10.7202/025561ar

Aller au sommaire du numéro

\section{Éditeur(s)}

Urgences

\section{ISSN}

0226-9554 (imprimé)

1927-3924 (numérique)

Découvrir la revue

Citer ce compte rendu

Fournier, D. (1989). Compte rendu de [Paul Chanel Malenfant, En tout état de corps, Trois-Rivières, Écrits des Forges, 1985, 80 p.] Urgences, (26), 118-119.

https://doi.org/10.7202/025561ar d'utilisation que vous pouvez consulter en ligne.

https://apropos.erudit.org/fr/usagers/politique-dutilisation/ 


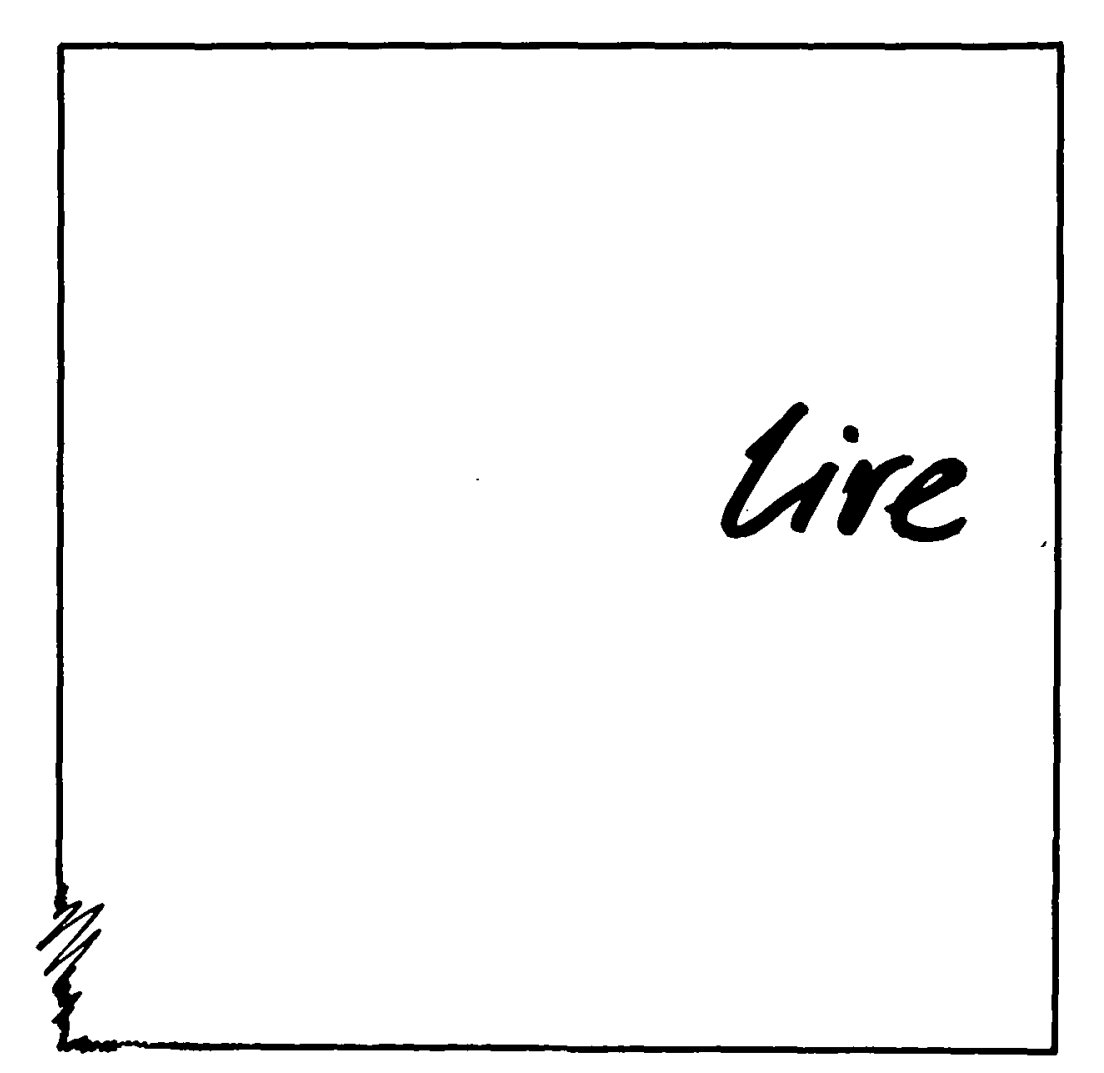


Paul Chanel Malenfant:

\section{En tout état de corps, Trois-Rivières, Écrits des Forges, 1985, $80 \mathrm{p}$.}

\section{Les noms du père suivi de Lieux dits: italiques, Saint-Lambert, Éditions du Noroît, 1985, 96 p. Coqs à deux têtes, Montréal, La nouvelle barre du jour, no 195, 1987, $64 \mathrm{p}$. Tirer au clair, Ed. du Noroît, 1988, 117 p.}

Le plus dur est toujours de commencer... de commencer par la mort, l'amour, et, de la, aller vers l'amour, aussi impossible soit-il. Theorique. Pourtant, ça n'empêche pas d'exister, la mort, l'amour et toutes ces choses de la naissance qui arrivent au corps depuis la langue, dans le langage, entre les pelures de la scène et celles du roman familial qui se tisse dans la vie.

Paul Chanel Malenfant dédouble le discours. Il dédouble ce discours déjà dédoublé par la parole. Il en fait le récit inénarrable d'une parole, que j'oserais situer sur le bout de la langue, d'une parole qui du corps va au corps, mais sans jamais s'y rendre autrement que dans la figure du Père.

Quatre livres pour me rendre compte que c'est ramenée à moi-même qu'il me conduit; que traversée par sa langue, je passe dans sa bouche mi-close ou mi-ouverte, dans une bouche dont la langue est brisée par la perte: la langue se perd, de la gorge aux seins, des lèvres aux gencives. La mère chante.

En tout état de corps, Les noms du père suivi de Lieux dits : italiques, Coqs à deux têtes et Tirer au clair, comment ne pas être, à un premier niveau, frappée et happé par l'extrême précision de la métaphore paternelle/corporelle?

Un premier réseau s'installe: d'abord le caractère typographique du texte: italique; puis, de faire son coq à l'âne, perdre la raison, le père à deux têtes: à tirer au clair que le nom, dont on se demande bien d'où il vient...

Précision: comment l'écriture peut-elle s'écrire en dehors du Père? et comment peut-elle se parler — en langues - en dehors du lieu italique corpsPère-coq? Dans l'autoportrait? Peut-être...

Et Les airs de famille...?

Qui n'a jamais regardé le monde familial depuis ses yeux d'enfant bien sûr n'entend pas le mal-enfant. Cette remarque est vaine puisque vivre, c'est regarder l'autre visage et vouloir le déposséder de ce qui est étranger. L'enfant est d'abord un étranger qui entend une langue étrangère. À cet égard, Les noms du père porte toute cette mise en abyme de la parole, du cri, de la voix, etc.

Du lien au lieu, la parenté s'amène contradictoire et contrariante. Mais du lieu au lien, la mort, celle d'un frère en particulier, ramène la voix silencieuse qui demande qu'on lui dise si elle lui parle encore... si elle parle de parler. Cette pensée est non seulement itinérante mais aussi itérative; elle se trompe même sur ce qu'elle raconte. 
L'entreprise d'écriture, de création en général, parle à l'être de ce qui l'intéresse: lui-même. On pourrait donc penser que l'anthropomorphisation, d'une certaine manière nécessaire, est en quelque sorte un leurre. La nature chez Paul Chanel Malenfant n'existe que filtrée par le corps, en ce qu'elle est touchée par le corps. En d'autres termes, on sait qu'il y a sujet d'état et sujet de faire. Les sujets d'état se définissent d'une part par leurs propriétés, mais surtout, on ne les reconnait que s'ils sont en relation avec des objets de valeur affective, bien entendu. Les sujets de faire demeurent un énoncé qui se situe entre les deux états: d'abord disjoint, ensuite conjoint, tout cela évidemment demeure dans la suite d'un geste ou d'une action, voire même une intervention qui détermine l'interstice du changement.

Ainsi le sujet dans le texte de Malenfant se trouve aux prises avec les objets partiels, mais aussi avec l'identification qui passe par le silence et le regard de la fille aux seins nus, personnage/objet de valeur affective qui revient sans cesse dans les quatre recueils. Ce personnage avec lequel s'entretient ce rapport affectif peut être indifféremment la sour comme le fantôme de la mère. Si elle terrorise depuis son origine sexuelle, du sang à la voix au regard, c'est pourtant par elle, c'est-à-dire à travers elle, que se parle une voix du faire, une voix étouffée et etranglée dans la gorge d'un féminin au lieu du corps tout aussi intime qu'animal.

Si lhomme parle de ne pas parler, la femme chante dans et hors la loi du langage: la langue paternelle regarde la langue maternelle, elle, elle se regarde et se laisse regarder. Le corps, chez Malenfant une langue, ramène au père, de la ride venue avec l'âge à la posture; le corps est ce qui rompt avant d'être brisé par la mort.

La langue n'est pas fouineuse. La langue est parole et ouvre le lieu fermé de la bouche aux lieux ouverts du texte qui se dit, qui s'inter-dit: passage, vecteur, axe, ou encore perspective du lieu du texte au texte du lieu débordant le clos et le forclos d'une histoire familiale qui, depuis son défaut de langue, amène le défaut dans la langue: le secret voilé, le secret dans le secret, le mensonge sans vérité. Oui, je dis ici sans vérité; l'audace de Paul Chanel Malenfant fait chair, fait retour du refoule. Il nous parle de nous-même. Il semblerait que ce soit là le paradigme, peut-être perdu, de son écriture: ce qui nous échappe reste pris dans la gorge de la mère et dans le regard du père. L'enfant a et la gorge et le regard. Et ce qu'il y perd, il le gagne puisqu'il est le point capiton, le point de chute; ce secret, de l'ordre du privé, ne cesse de se crier, de se hurler en quelque sorte au risque non pas de devenir public, mais de devenir l'enjeu du chantage amoureux. En effet, comment aimer, nous ordonne le texte, c'est-à-dire comment ne pas s'approprier le corps, la voix, le regard et surtout le recit de l'autre.

Comment aimer? Bien sûr, on pourrait extrapoler le lexique, le glossaire thematique, puisque les mots forment des isotopies qui tournent bien autour des deux guerres, de la mort comme de la naissance, de la politique familiale et, surtout, de l'histoire: celle qu'on se raconte à deux, celle qu'on raconte a un/e autre, celle qu'on se raconte, celle qu'on raconte, etc.

Paul Chanel Malenfant commence de commencer l'origine, celle du fantasme de déplacement. Son écriture, à mesure qu'elle nomme, s'en éloigne et s'en rapproche. La troublante figure paternelle trouve sa voix en la voix de la mère. Á cet égard, le bouleversement est total et singulier. 